\title{
Forgiveness and Its Relationship with Marital Satisfaction: \\ A Sectional Study
}

\author{
Zahra Askari $^{1 *}$
}

\section{ABSTRACT}

Introduction: forgiveness is one of the new issues in the scope of family treatment that in recent decades entered the scopes of psychology and family consultation. Purpose: the present study has done with aim of investigating the relationship of forgiveness index with marital satisfaction. Method: this study with a causal-comparative framework was done in domain of descriptive studies. To this aim eighty couples $(\mathrm{N}=160)$ from residents of region 2 and region 5 of Tehran city (age range of 18-31 with average age of 20.6) were selected by multiphasic cluster sampling. The data collected through survey and to this aim two questionnaires of measurement of couples' impunity (response rate=89\%) and marital satisfaction questionnaire (response rate=91\%) were used. The data were analyzed through Pearson parametric correlation test and t-test. Moreover the qualitative data resulting from demographic evaluations were codified and were analyzed by analysis instrument of qualitative data i.e. Atlas.ti-5.2. Findings: the findings resulted from data analysis represented that there is significant relationship between two indices of forgiveness and marital satisfaction $(\mathrm{P}<0.05)$. Besides, the forgiveness index determined 0.40 of variance changes in marital satisfaction variable. Conclusion: the respective findings while including applicable implications can be of high importance in prevention and intervention perspective.

Keywords: Marital Satisfaction, Forgiveness, Sectional Study

Forgiveness is one of the new debates in family treatment scope that during the recent decades entered the scope of psychology and family counseling. This factor of forgiveness is one of the variables that have today attracted the attention of researchers in the scope of couples' conflicts. Forgiveness is the sub fruit of healing process that reflects positive self-esteem. The necessity and need of forgiveness begins with an emotional wound; a wound that bypasses physical, moral and psychological privacies and territories. Versington (2000) believes that family members annoy each other; this means that in familial relationships resentment is unavoidable. This is the place where the issue of forgiveness comes in. De Blasio and Procter (1993) found that

\footnotetext{
${ }^{1}$ M.A in psychology, Islamic Azad University, Science And Research Branch, Tehran, Iran *Responding Author

(C) 2016 I Z Askari; licensee IJIP. This is an Open Access Research distributed under the terms of the Creative Commons Attribution License (http://creativecommons.org/licenses/by/2.0), which permits unrestricted use, distribution, and reproduction in any Medium, provided the original work is properly cited.
} 


\section{Forgiveness and Its Relationship with Marital Satisfaction: A Sectional Study}

forgiveness helps in improving the relationships, appropriate strategy of anger, healing of emotional wounds. Some believe it has contradictory nature that result in personal development. Fincham et al. (2007) also showed in a research women who got high scores in impunity; their partners have reported lower marital conflicts. The process of impunity is defined as the process of intentional overlooking of the right of getting angry and hateful of a harmful action where the annoyed person takes a warm and passionate behavior toward the trespassing person. Simon and Simon (1371) in defining the features of forgiveness state that forgiveness is an unconditional act that happens without any expectation of compensation from the other side and it is valuable by itself. With regard to what we have considered we intend to evaluate the relationship between forgiveness and marital satisfaction index with a hope that the findings in connection with mainstream research opens new promising perspectives in this scope.

Marital satisfaction refers to happiness and enjoyment from the relationship among couples. Marital satisfaction means having appropriate and satisfied feeling from marriage. Marital satisfaction is one of the most important determinant factors of safe function of family institute (Greef, 2000). In other words, one of the most important factors of marital system is the satisfaction that espouses experience in their marriage. Marital satisfaction can be considered as a psychological condition that doesn't appear automatically but requires both sides' efforts. Especially in the early years after the marriage, marital relationship is very unstable and satisfaction is in its riskiest state.

Conception of wife or husband from the amount, intensity and range of problems in the relationship reflects their level of satisfaction. Regarding the relationship of spirituality and marital satisfaction and regarding the importance of issue it is enough to say that after the first half of the twentieth century, there were 200 researches about the relationship of religion and health that at the end of this century suddenly this number raised to more than 5000 researches which confirms the positive relationship of religion and health. Today, this issue is developing very rapidly in a way that it can be regarded as «scientific revolution» (King, 2009). Today the concepts of spiritual health, spiritual change and spiritual well-being are entered the psychological academic literature in the threshold of the third millennium.

With respect to what we have considered and with respect to modern approach in the scope of psychology in the twenty first century, we intend to evaluate the relationship between Forgiveness and marital satisfaction index. We hope that the findings of this research in connection with mainstream research open new promising perspectives in this scope.

\section{Estimation of the size of sample}

With respect to the fact that the statistical method in this research is correlational and in studies of correlation of sample size, 20 to 40 subjects for each variable must be considered, therefore by 
allocation of 40 couples of subjects to each variables of research, 80 couples of subjects were used in this study.

$$
N=2 \mathrm{q}=2 \times 40=80
$$

\section{Statistical analysis}

In this study with regard to the nature of the study and previous investigations and with the aim of investigating the relationship between two variables of forgiveness and marital satisfaction and with respect to interval nature of these two measures, Pearson parametric analysis test was applied and the meaningfulness of the relationship was determined by $t$-test.

\section{Ethical Principles}

In this study, the informed consent was obtained without coercion, threat, enticement and seduction and their decision to refuse or accept to participate in the study were respected. It was also tried that the research methods do not contradict with the religious and cultural principles of the participants and the participants were respected in all stages of design, implementation and reporting in terms of human dignity, respect and protection of their physical and mental integrity so that conducting the research would not delay in the process of medical care for the participants.

\section{METHOD}

The present study is of causal comparative and correlational kind and is in the realm of descriptive studies. The data of the present study were collected during khordad 1 and Esfand 1 of 1391using survey and in form of questionnaire and clinical interview. To this aim 160 subjects in form of 80 couples were selected by multiphase cluster sampling. The method of data collection was survey and in order to estimate indices of forgiveness and marital satisfaction, Marital of Forgiveness Scale and Enrich questionnaires were applied respectively. The collected data were analyzed by Pearson correlation test and F-test. The collected data resulting from demographic evaluations were codified and were analyzed by instrument of analysis of qualitative data ATLAS.ti - 5.2.

\section{Instruments}

-Marital of Forgiveness Scale (MOFS): this questionnaire was designed by Paleari et al. (2009) so as to evaluate forgiveness process in marital context of life. The scale contains 10 statements and two subscales of benevolence and anger avoidance. For normalization of this scale, it was administered to 328 couples. The results of normalization research and evaluation of psychological characteristics represents appropriate reliability of this scale. Coefficient of Cornbach's alpha of subscales of benevolence were reported $80 \%$ and $75 \%$ for men and women respectively and that of anger-avoidance subscale were reported $83 \%$ and $79 \%$ for men and women respectively. Divergent validity of this scale was investigated by using confirmatory 
factor analysis method and the results also confirmed the existence of two separate but congruent factors of benevolence and anger avoidance.

-Enrich couple measure: this questionnaire has 35 Likert options that applies in order to evaluate potential problematic grounds or to determine strong and positive grounds in marital relationship. Enrich couple questionnaire has been administered on 25501 married couples in 2000 by David Elson and Amy Elson. Alpha coefficient of questionnaire for sub-measures of marital satisfaction, relationship, conflict solution, and changing desire was $0.86,0.80,0.84$, and 0.83 respectively and test-retest validity of questionnaire for each subtest was reported as 0.86 , $0.81,0.90$, and 0.92 respectively. Alpha coefficient of questionnaire in the study of Asoudeh(1389) with 365 couples (730 person) was obtained as 0.68 (with deletion of question number 24 alpha becomes 0.78), 0.78, 0.62, 0.77 respectively. In Iran also studies of Moradi(1380), Sanayee (1381), Hagh Shenas (1383) represented that Enrich measure and its equivalent Persian translation has necessary reliability and validity.

\section{RESULTS}

\section{Statistical indices}

Table 1: Distribution of subjects based on levels of education

\begin{tabular}{|c|c|c|c|}
\hline Index & frequency & percent frequency & cumulative frequency \\
\hline below diploma & 7 & 4.4 & 4.4 \\
\hline diploma & 54 & 33.8 & 38.1 \\
\hline Associate Degree & 16 & 10 & 48.1 \\
\hline bachelor degree & 74 & 46.3 & 94.4 \\
\hline License & 7 & 4.4 & 98.8 \\
\hline PhD & 2 & 1.3 & 100 \\
\hline sum & 160 & 100 & - \\
\hline
\end{tabular}

As it is seen in table1, most of the subjects of the research were individuals with bachelor degree $(46,3)$ and after that were individuals with educational level of diploma $(33,8)$. Frequency distribution of subjects based on parameter of age is given in table 2.

Table 2: Distribution of subjects based on levels of age

\begin{tabular}{|c|c|c|c|}
\hline Index & frequency & percent frequency & cumulative frequency \\
\hline $18-30$ & 62 & 38.3 & 38.8 \\
\hline $31-40$ & 53 & 33.1 & 71.9 \\
\hline $41-50$ & 29 & 18.1 & 90 \\
\hline $51-60$ & 13 & 8.1 & 98 \\
\hline $61-70$ & 3 & 1.9 & 100 \\
\hline sum & 160 & 100 & - \\
\hline
\end{tabular}

Based on represented results in table 2, most of the participants of the research are in the age range of $18-30(38,3)$. Furthermore, $33.1 \%$ which is equivalent to 53 subjects are in the age range of 31-40. 


\section{Kolmogorov Smirnov test}

As you know, one of the pre-requisites of using parametric tests is normality of the distribution of research variables. In order to investigate the above pre-requisite Kolmogorov-Smirnov test was applied that the results are represented in table 3.

Table 3: results of Kolmogorov Smirnov test

\begin{tabular}{|c|c|c|}
\hline Variable & Z & Sig. \\
\hline marital satisfaction & 0.74 & 0.44 \\
\hline Spirituality intelligence & 0.81 & 0.41 \\
\hline
\end{tabular}

With respect to results of table 3 , it can be concluded that the entire variables were normalized; therefore, parametric tests can be used to investigate the research hypotheses.

\section{Evaluation of equality of variances}

As you know one of the prerequisites of using parametric tests is the equality of variances of error. Table 4 represents the results of Leven test.

Table 4: results of leven test

\begin{tabular}{|c|c|c|}
\hline \multirow{2}{*}{ Variable } & \multicolumn{2}{|c|}{ Leven test } \\
\cline { 2 - 3 } & F & Sig. \\
\hline marital satisfaction & 2.302 & 0.09 \\
\hline forgiveness & 1.712 & 0.30 \\
\hline
\end{tabular}

With regard to results of table 4 , variances of variables of forgiveness and marital satisfaction are equal $(\mathrm{P}<0.05)$.

Table 5: results of Pearson test

\begin{tabular}{|c|c|c|c|c|c|}
\hline Variable & $\begin{array}{c}\text { Kind of } \\
\text { correlation }\end{array}$ & correlation & direction & $\mathbf{R}^{2}$ & Sig. \\
\hline $\begin{array}{c}\text { forgiveness } \\
\text { and marital } \\
\text { satisfaction }\end{array}$ & Pearson & 0.494 & Positive & 0.244 & 0.03 \\
\hline
\end{tabular}

With regard to above table and the extent of obtained correlation (0.494) it can be concluded that there is a meaningful relationship between forgiveness index and marital satisfaction.

\section{DISCUSSION}

The study that has just been considered was done with the aim of investigating the relationship between two variables of forgiveness and marital satisfaction. The results of this study showed that there is a statistically meaningful relationship between two respective indices. Review of research literature reveals theoretical and scientific support of findings of this research. In this line Afkhami et al. (1386) in a study with the theme of investigating the relationship between forgiveness and couples' marital conflicts, represented that there is relationship between marital conflicts and forgiveness in three subscales of realistic understanding, determination and

(c) The International Journal of Indian Psychology, ISSN 2348-5396 (e)| ISSN: 2349-3429 (p) | 88 


\section{Forgiveness and Its Relationship with Marital Satisfaction: A Sectional Study}

confirmation of mistake and compensation of wrong action. Also a significant relationship was observed between forgiveness and marital conflicts in subscales of individual or singular relationship with ones' own relatives and family relationship with espouse's relatives and friends. Khojasteh mehr et al. (1387) in a research compared continuity, adaptability, level of relationship and marital satisfaction of more generous and less generous married people. The results showed that more generous married people have meaningfully more continuity, adaptability, level of relation and marital satisfaction in comparison with low generous married people.

Ehtesham zadeh et al. (1389) in a research investigated the relationship of forgiveness, perfectionism and intimacy with marital satisfaction of self-sacrificing couples of Ahvaz city. The results revealed that there is a positive relationship between forgiveness and marital satisfaction. The study that has been done by Nouri (1389) with theme of forgiveness and the extent of marital satisfaction represented that there is a meaningful relationship between forgiveness and marital satisfaction. Moreover those couples who have applied forgiveness in their relationships reported higher levels of marital satisfaction. In the study of Soudani et al. (1387) religiousness and forgiveness predicted marital satisfaction. Khodayarifard et al. (2002) investigated in a research the application of forgiveness method with religious emphasis in treatment and improvement of inter-personal relationships. The findings of this study revealed that with implementation of this method offended people could gradually decrease negative thoughts and feelings toward that annoying person and replace it with positive alternatives. Gorden et al. (2009) in their study showed that couples' forgiveness is related to their marital satisfaction and their performance in their life. This study was done with the aim of evaluating the relationship between two variables of forgiveness and marital satisfaction. The results of the study showed that there is statistically significant relationship between the respective variables. The findings of this study can capture attention in application of theoretical frameworks.

\section{LIMITATIONS OF THE STUDY}

In the process of conduction, this study was together with some limitations that are as follows: 1 ) some of the participants were unwilling to participate in this study and since one of the requirements of this study was voluntary participation of patients, some of the patients didn't participate in this study.

\section{CONFLICT OF INTERESTS}

The author declared no conflict of interests.

\section{ACKNOWLEDGMENTS}

The author appreciates all those who participated in the study and helped to facilitate the research process. 


\section{REFERENCES}

Afkhami I, Bahrami F (1387). The effect of training forgiveness on the extent of forgiveness of couples of Yazd city, modern educational thoughts, fall 89, sixth ed., N. (3):9-26.

Diblassio, F. A \& Proctor, B. B (1993). Therapists and the clinical use of forgiveness American,Journal of family therapy,21, 175-187.

Ehtesham Z, Parvin T (1389). The relationship of personal characteristics and dependence methods with forgiveness of staff of Oil Company of Ahvaz city, new findings in psychology, Sixth year, Summer 1390, N. (18), p. 87-102.

Fincham ,F. D. \& Steven, R. H (2004). Forgiveness and conflict resolution in marriage. Journal of Family Psychology, 18, 72-81.

Greef, A \& Bruyne,T (2000). Conflict management style and marital satisfaction. Journal of sex and marital therapy,26,321-334.

Khodayarifard M, Ghobari Bonab B, Faghihi Ali N, Vahdat Torbati S (1381). The treatment method of forgiveness with an emphasis on Islamic perspective: Case study. Thought and behavior, 1381, eighth year, N. (1).

Khojasteh Mehr Gh, Abbaspour Z, Rajabi Gh (1387). Comparison of continuity, adaptability, level of relationship and marital satisfaction of high generous married people with less generous counterparts of staffs of Ahvaz offices, journal of educational science and psychology, Spring,1387;15(periodical):179-194.

Nouri Tirtashi E (1389). Forgiveness and the extent of marital adaptation, Two periodicals of Iran community of psychology, fifth ed., P. 775-777.

V Fatemi, S Hoseiniyan (2016), Study of Locus of Control in Female and Male MSc Students, International Journal of Indian Psychology, Volume 3, Issue 3, No. 9, DIP: 18.01.154/20160303, ISBN: 978-1-365-13820-1

Worthington , E. L (2000). The psychology of unforgiveness and forgiveness and implications clinical practice, Journal of Social and clinical psychology,18, 358-418.

How to cite this article: Z Askari (2016), Forgiveness and Its Relationship with Marital Satisfaction: A Sectional Study, International Journal of Indian Psychology, Volume 3, Issue 3, No. 10, DIP: 18.01.181/20160303, ISBN: 978-1-365-19879-3 